\title{
The use of Mobile Phones in Strengthening Health and Demographic Data Collection by Community key Informants: Experiences from the Kintampo Health and Demographic Surveillance System
}

\author{
Edward Anane Apraku, Abubakari Sulemana, Francis Dzabeng, Awurabena Quayeba Dadzie, Ernest \\ O. Nettey, Gifty Fosuah Nuamah, Abukari Mahama, Samuel Afari-Asiedu, Emmanuel Mahama, \\ Charles Zandoh, Kwaku Poku Asante, Seth Owusu-Agyei
}

\begin{abstract}
Identification and reporting of vital events such as births and deaths remain a challenge within communities in low-and middle-income countries (LMICs). LMICs are recently experiencing high mobile phone penetration. This study, therefore, explored the feasibility of Community Key Informants (CKIs) using mobile phone technology to improve reporting of vital events at the community level. Sixty CKIs were purposively sampled from the Kintampo Health and Demographic Surveillance System (KHDSS) setting based on mobile phone ownership. CKIs were grouped into an intervention and a control group. The intervention arm was provided with mobile phone air time to report vital events that occurred in their communities. The control group used the routine system of reporting in the KHDSS. The number of vital events reported by CKIs increased at the end line compared to baseline: (pregnancy: $40.25 \%$ to $72.80 \%$; birth: $56.52 \%$ to $69.80 \%$; deaths: $33.33 \%$ to $68.60 \%$ ). The time interval between event identification and reporting was much shorter for the intervention group at the end line compared to baseline: (Intervention: 95.06 days to 31.35 days, Control: 87.54 days to 80.57 days). This study demonstrated the feasibility of CKIs using a mobile phone in reporting vital events more timely and effectively.
\end{abstract}

Keywords: Community key informants, mobile phones, vital events, Kintampo health and demographic surveillance system.

Manuscript received on September 29, 2021.

Revised Manuscript received on December 09, 2021.

Manuscript published on December 30, 2021.

* Correspondence Author

Edward Anane Apraku*, Health and Demographic Surveillance System, Kintampo Health Research, Box 200 Kintampo, Ghana. Email: edward.apraku@khrc.org

Dr. Abubakari Sulemana, Kintampo Health and Demographic Surveillance System Kintampo Health Research, Box 200 Kintampo, Ghana. Email: abubakari.sulemana@khrc.org

Francis Dzabeng*, West African Centre for Cell Biology of Infectious Pathogens, University of Ghana, Ghana. Email: francis.dzabeng@gmail.com

Awurabena Quayeba Dadzie, World Vision Ghana, Accra, Ghana. Email: awurabs68@gmail.com

Ernest O. Nettey, Regional Institute for Population Studies, University of Ghana. Accra, Ghana Email: kojoernest@yahoo.com

Gifty Fosuah Nuamah, Health and Demographic Surveillance System, Kintampo Health Research, Kintampo, Ghana. Email: maabena.gn@gmail.com

(C) The Authors. Published by Blue Eyes Intelligence Engineering and Sciences Publication (BEIESP). This is an open access article under the CC BY-NC-ND license (http://creativecommons.org/licenses/by-nc-nd/4.0/)

\section{INTRODUCTION}

Identification and reporting of vital events such as births and deaths at the community level remain a challenge in between local and national population censuses (1). Consequently, key vital events such as births and neonatal deaths are under-reported. Without information on the number of births, deaths, and causes of death by age, sex, and geographical distribution, it is challenging to gauge the success of health programs such as whether a country is reducing child and maternal mortality as articulated in the health targets of the Sustainable Development Goals (SDG)(2). Earlier studies have examined Community Key Informants (CKI) motivation, retention, and incentives (3). Other studies have provided insights into monetary incentives (4), and evidence suggests that modest compensation can increase volunteer study participation rates (4). However, few studies have investigated the feasibility of community volunteers using mobile technology in data collection in LMICs. Health and demographic surveillance system (HDSS) platforms are currently being used in LMICs to collect longitudinal health and demographic data for a dynamic cohort of the total population in a given geographic area (5-8).

Abukari Mahama, Kintampo Health and Demographic Surveillance System, Kintampo Health Research, Box 200 Kintampo, Ghana. Email: mahamahdss@khrc.org

Samuel Afari-Asiedu, Environmental Health and Related Studies, Kintampo Health Research, Box 200 Kintampo, Ghana. Email: samuel.afari-asiedu@khrc.org

Emmanuel Mahama, The Global Fund NFM II West Africa Program to Combat AIDS and STI, Accra, Ghana. Email: emmanuelmahama@gmail.org

Charles Zandoh, Kintampo Health and Demographic Surveillance System, Kintampo Health Research, Box 200 Kintampo, Ghana. Email: charles.zandoh@kintampo-hrc.org

Dr. Kwaku Poku Asante, Kintampo Health and Demographic Surveillance System, Kintampo Health Research, Box 200 Kintampo, Ghana. Email: kwakupoku.asante@kintampo-hrc.org

Prof. Seth Owusu-Agyei, Institute of Health Research, University of Health and Allied Health Sciences, Ho, Ghana Email: sowusuagyei@uhas.edu.gh

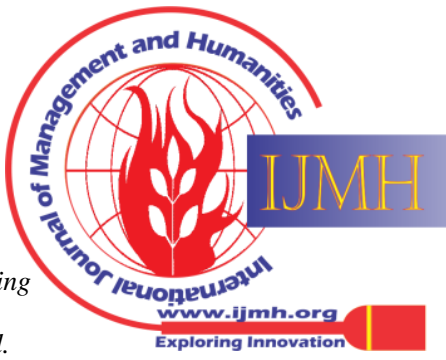


The use of Mobile Phones in Strengthening Health and Demographic Data Collection by Community key Informants: Experiences from the Kintampo Health and Demographic Surveillance System

An innovative component of the HDSS is the CKI system where well-known individuals in the various communities are trained to enable them to record any pregnancy, birth outcomes, and deaths that occur in their respective communities for a little fee.

Their activities are important because some respondents do not report particularly pregnancy loss through miscarriage or abortion and neonatal deaths during the fieldworkers' visits. However, with the presence of the CKIs in the communities who record such events and in turn report them to the fieldworker, this challenge is largely reduced or overcome completely. High mobile phone penetration in LMICs recently offers an opportunity for health researchers to acquire data in real-time to reduce the lapses that are associated with data miss out (9).

According to the World development report 2016, more households in LMICs own mobile phones than have access to electricity or clean water, and nearly 70 percent of the bottom fifth of the population in developing countries own mobile phones (10). The ever-growing and increasing use of mobile and wireless technologies in achieving health objectives have the potential of transforming health service delivery in LMICs (11).

Considering the availability and use of mobile phones in our communities, this study explored the feasibility of using mobile phones in strengthening data collection by CKIs in the Kintampo Health and Demographic Surveillance System (KHDSS) coverage area.

\section{METHODS}

\section{A. Study Area}

The study was conducted in the Kintampo North Municipality and Kintampo South District in the Bono East region in the central part of Ghana. The study area is covered by the KHDSS, operated by the Kintampo Health Research Centre (KHRC). It is located in the Forest-Savannah transition zone of Ghana with a land size of 7,162 km2 (6). Majority of the inhabitants are into subsistence and small-scale commercial farming.

The districts have an estimated resident population of about 156,145 as of 2016 (12). The population is largely rural with about 25.8 percent of the total population having access to electricity, which is predominantly available in the urban areas (6). The KHDSS allows for periodic censuses to record the dynamics of human populations in the study area. The KHDSS mainly monitors three indicators of the population: fertility, migration, and mortality.

This is achieved through at least two visits each year to households within the KHDSS coverage area. Also, the KHDSS collects information on household socio-economic status and conducts a verbal autopsy on each death to ascertain the probable causes of deaths $(6,12,13)$. Fig. 1 . presents the graphical presentation of the study area.

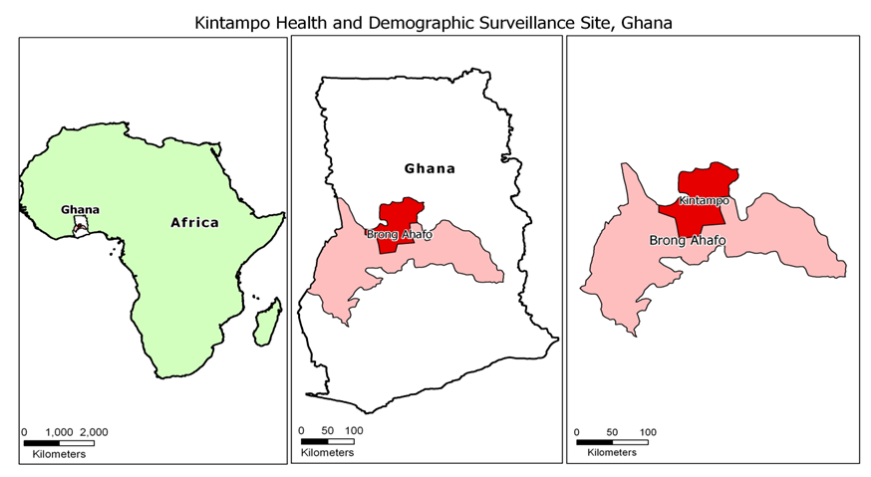

Fig. 1. A map showing the Kintampo Health and Demographic surveillance site in red.

\section{B. Study Population}

CKIs, also known as Community Health Workers (CHWs), Community Health Volunteers (CHV) Community Based Surveillance Volunteers (CBSVs), Village Health Workers (VHWs), Volunteer Community Health Workers (VCHWs) and their potential for collecting data has been explored by many studies were the primary participants for this study (14-16). The KHDSS currently covers 161 communities with 181 active CKIs. The primary role of the CKIs includes identification and recording of vital demographic events such as pregnancies and pregnancy outcomes (stillbirth, lost before six 'months, ectopic) and deaths (neonatal, infant, child, and adult deaths) within their communities. They are visited by KHDSS field supervisors (FS) bi-weekly to verify and transcribe the written information from the CKIs records for data entry (6). The Ghana Health Service presently employs the services of CKIs to monitor a wide range of disease surveillance in addition to mobilizing their community members for outreach programs (17). Their work complements health facility-based surveillance, and are vital in the implementation of the Community-Based Health Planning and Services (CHPS) strategy (18). Conventionally, vital events include live birth, death, fetal death, marriage, divorce, annulment, judicial separation, adoption, legitimation, and recognition (19). However, this study limited vital events to pregnancy, birth, and death.

\section{Study Procedure}

The study employed a cross-sectional comparative design, where two groups were studied. As a proof of concept, a total of 60 CKIs were randomly sampled out of 181 active CKIs and divided into two groups an intervention and a control group. Each group was made up of 30 CKIs. For communities with more than two CKIs, only two were selected. All the 60 CKIs were tasked to collect vital demographic events that occur in their communities. The study lasted for four months starting from 8th December 2014 to 8th April 2015. Mobile phone air time was provided to the intervention group to report identified events. The intervention group was trained on how to report events with the mobile phone (voice call).

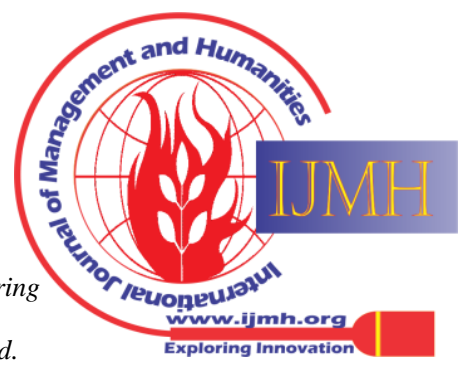


The calls were received by a research officer at the office who then records the events on a designed data collection form. The control group did not receive any mobile phone air time. They only entered the events they identified in their notebooks as part of the KHDSS routine processes.

All CKIs in the intervention group were given an initial flat rate mobile phone air time voucher of the same amount. Subsequent air time was provided based on the number of events the CKI reported. All the CKIs in the study were visited once every two weeks as routinely done in the KHDSS.

Data extraction forms were developed to record data of pregnancies, pregnancy outcomes, deaths, gender, name, community name, and compound identification numbers. Also, information concerning the time an event occurred, event date, and time event was reported.

The forms were completed by a research officer any time a CKI called and dictated the information through the mobile phone. Events recorded by CKIs in the control group were extracted and verified by an FS during scheduled visits.

The study used four months of retrospective events collected as part of KHDSS database by both the intervention and the control groups as baseline data.

\section{Data Management and Analysis}

All forms were thoroughly checked for completeness and consistency before it was logged in for data entry. The data were double entered by trained data entry clerks into a password-protected database in Microsoft Visual Fox Pro 9(20) and managed by a data manager. Queries that emanated during data entry were sent back to the field for resolution.

The data was then verified for accuracy and transferred to STATA 14.0 for analysis. Descriptive analysis was used to summarize the socio-demographic characteristics of study participants. The mean number of days for identification of events, the time an event occurred to the time the event was identified, the time an event identified to the time a field supervisor visited, the time an event occurred to the time a field supervisor visited, the time an event was identified to the time a call was placed, and the time an event occurred to the time a call was placed were computed using STATA 14.0 (21).

Bar charts were generated using Microsoft excel 2010 to compare the number of vital events (specific types) collected by the two groups at baseline and end line. Bar charts were also plotted to highlight the challenges CKIs faced in their attempt to place a call at the time an event was identified.

\section{E. Ethical approval and consent to participate}

Ethical approval was sought from the KHRC Institutional Ethics Committee. The KHRC IEC reviewed the study protocol and all instruments used in the implementation of the study: Ref KHRC/IEC/ICF/2014-12.

Written informed consent was obtained from CKIs. For a CKI who could not read and write, the informed consent was witnessed by a third person who was known by the CKI and countersigned.

\section{F. Study Limitation}

It is difficult to make causal inferences in this study. Seasonality of events and size of communities in both arms were not controlled for. The study could not provide CKIs with mobile phones. CKIs used their phones which may conflict with their private calls. The study did not examine CKI motivation for reporting events.

\section{RESULT}

\section{Demographic characteristics of participants}

As shown in Table I, the study participants were adults between the ages of 26 and 65 years old. The majority of participants (35.0\%) were between the age group 56 and 65 years, and the lowest proportion of participants (16.7\%) were between the age group 26 and 35 years.

Approximately, eighty-eight percent (88.3\%) of the participants were males. Most of the participants (68.3\%) had completed middle or Junior High school (JHS) level education. Sixty-five percent (65\%) of the participants were Christians.

Table- I: Background characteristics of CKIs

\begin{tabular}{|c|c|c|}
\hline Characteristics & Number(60) & Percent \\
\hline \multicolumn{3}{|l|}{ Age group } \\
\hline $26-35$ & 10 & 16.7 \\
\hline $36-45$ & 15 & 25.0 \\
\hline $46-55$ & 14 & 23.3 \\
\hline $56-65$ & 21 & 35.0 \\
\hline \multicolumn{3}{|l|}{ Gender } \\
\hline Male & 53 & 88.3 \\
\hline Female & 7 & 11.7 \\
\hline \multicolumn{3}{|l|}{ Education level } \\
\hline None & 1 & 1.7 \\
\hline Primary & 1 & 1.7 \\
\hline Middle School/JSS & 41 & 68.3 \\
\hline Secondary & 11 & 18.3 \\
\hline Post-Middle College & 3 & 5.0 \\
\hline University & 3 & 5.0 \\
\hline \multicolumn{3}{|l|}{ Religion } \\
\hline Christian & 39 & 65.0 \\
\hline Muslim & 15 & 25.0 \\
\hline Traditional & 2 & 3.3 \\
\hline Other & 4 & 6.7 \\
\hline
\end{tabular}

Comparison of the number of pregnancies reported at baseline and end line

At baseline, CKIs in the control group recorded 141 (59.75\%) pregnancies whilst those in the intervention group recorded 94 pregnancies (40.25\%). However, at end line, the control group recorded $68(27.20 \%)$ pregnancies whilst the intervention group recorded 185 (72.8\%) when mobile phone air time was introduced as an intervention as shown in Fig. 2.

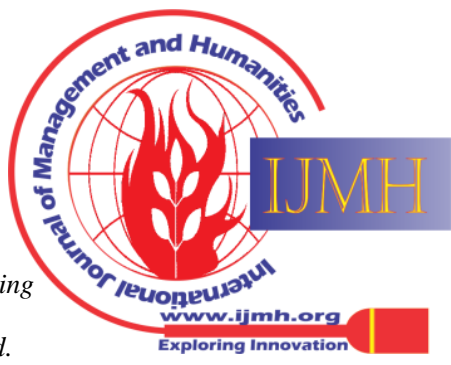


The use of Mobile Phones in Strengthening Health and Demographic Data Collection by Community key Informants: Experiences from the Kintampo Health and Demographic Surveillance System

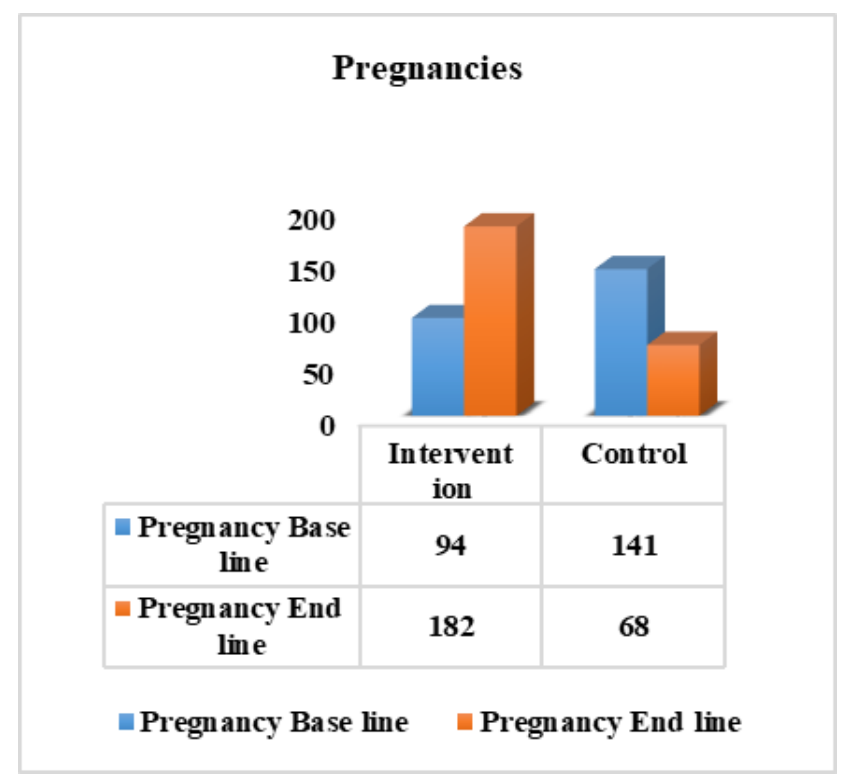

Fig. 2. Comparison of recorded pregnancies reported at Baseline and End line

A.Comparison of the number of births reported at baseline and end line

At baseline, CKIs within the control group reported 70 (43.5\%) births whilst those in the intervention reported 91 (56.5\%) births. At the end line, the control group reported 80 (30.2\%) births whilst the intervention group reported 185 (69.8\%) births as shown in Fig. 3.

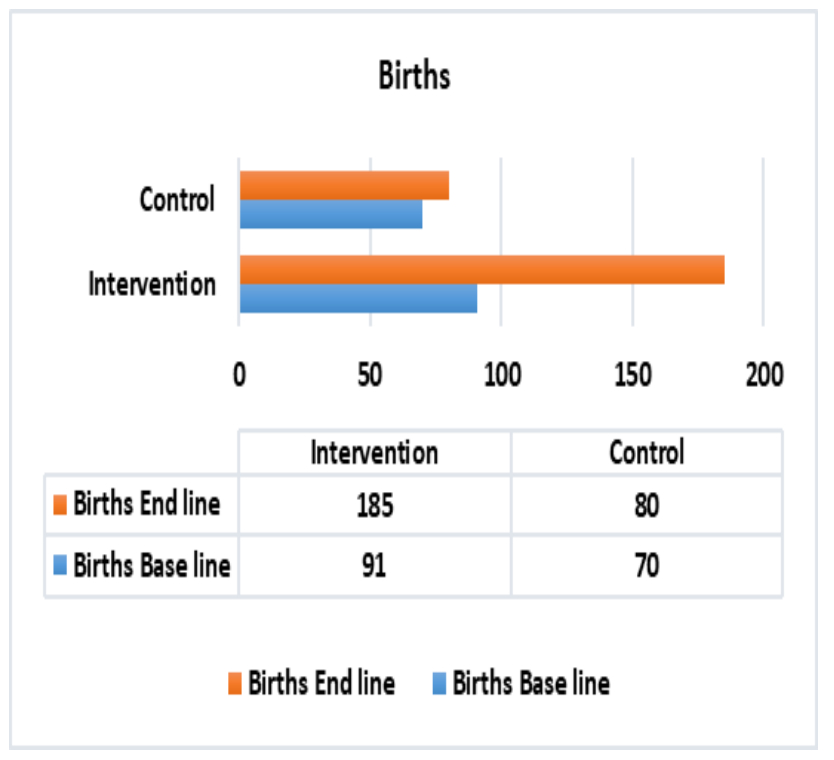

Fig. 3. Comparison of recorded births reported at Baseline and End line

B. Comparison of the number of deaths reported at the baseline and end line

At baseline, CKIs in the control group reported 10 $(66.67 \%)$ deaths whilst those in the intervention group reported 5 (33.33\%) deaths. In the end line, however, the control group reported 22 (31.4\%) deaths while the intervention reported 48 (68.6\%) deaths as shown in Fig. 4.

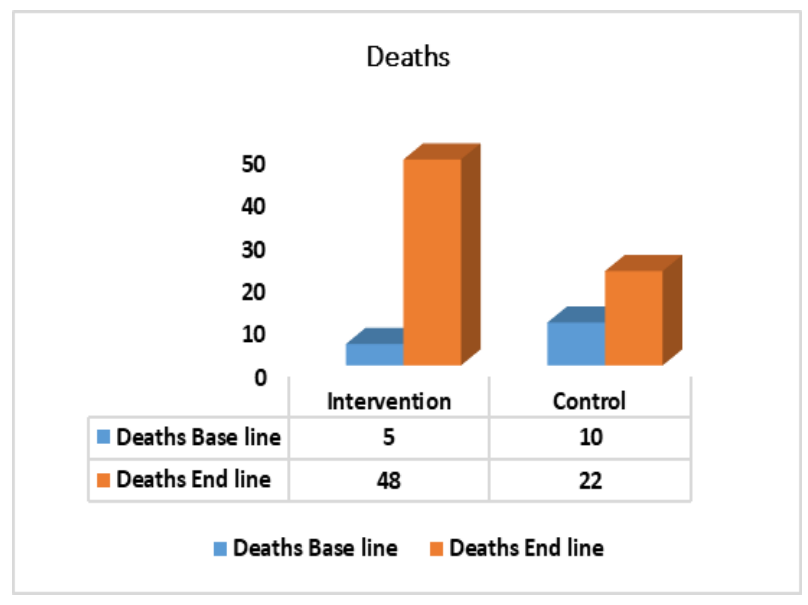

Fig. 4. Comparison of recorded deaths at Baseline and End line

C.Summary statistics of event type reported by CKIs in the intervention and control groups at baseline (in days)

From Table II, it took the intervention group 65.3 days on average at baseline to identify pregnancy. On the other hand, the control used an average of 56 days at baseline to identify pregnancy. For births, it took the intervention group 3.1 days on average at baseline to identify birth and it took the control 1.2 days on average at baseline to identify a birth. The average number of days used by both arms in the identification of deaths was the same (0.6 days) at baseline. In general, it took the intervention and control group on average 10.6 and 15.2 days respectively at baseline to identify an event when it occurred.

D.Summary statistics of event type picked by CKIs in the intervention and control group at end line (in days)

From Table III, the intervention group used an average of 149.2 days to identify a pregnancy whilst the control used 138.1 days to identify pregnancy. The average duration of time for CKIs in the intervention group to call and report pregnancies was shorter (36.5 days) compared to (77.1 days) for the control group.

For births, the intervention group used an average of 25.3 days to identify a birth event whilst the control group used 4.46 days to identify births. It took the intervention group 28.74 days on average to call and report a birth.

For deaths, the intervention group used 5.3 days on average to identify a death whilst the control used 1.2 days. In the case of reporting of deaths, it took on average 22.2 days for the intervention group to call and report a death, on the other hand, it took 110.45 for a field supervisor to visit a CKI to record a death. The average time duration of reporting a death was shorter (28.7 days) in the intervention group compared to 75.3 days for the control group

In general, it took an average of 76.8 days for those in the intervention group to identify events whilst those in the control used 55.9 days on average to identify events. CKIs in the intervention group reported events more-timely after identification than the control group who were visited by a field supervisor.

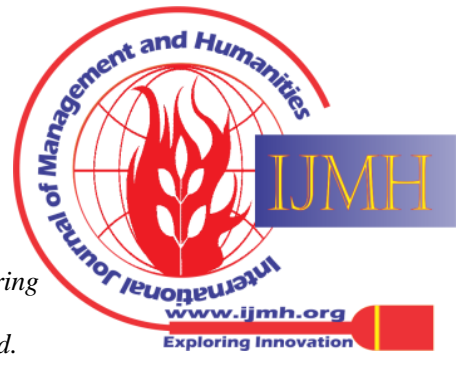




\section{E. Challenges for not reporting an event at the time of identification by the Intervention group}

The major challenges for not reporting an event at the time of identification by the intervention group were the inability to reach the office by phone (48\%), and network failure (40.4\%). The other challenges together fell below 5\% except for "Other" reasons (6.9\%). The study did not repair or replace faulty phones for the CKIs when they had problems with them. CKIs who had problems with their phones within the study period reported events that they have identified after their phones were repaired. Fig. 5. shows a bar graph of the challenges for not reporting an event at the first time of event identification by the intervention group.

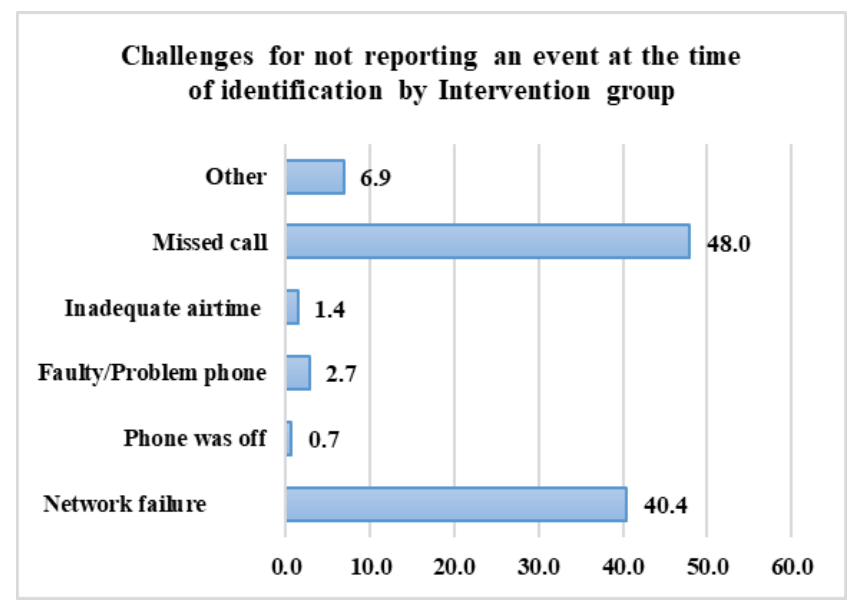

Fig. 5. Challenges encountered for not reporting an event at the time of identification by the intervention group

\section{DISCUSSION}

Overall, the findings demonstrated the feasibility of CKIs using a mobile phone to collect and report vital events. Information technology has a huge part to play in improving registration of vital demographic events at the community level, and provide data for the district, regional and national levels (17). Mobile phone-based surveys have other advantages and disadvantages that may be particularly important to researchers (14). The near-real-time access to data as a result of the introduction of mobile phone technology may improve data quality as data reported by the intervention group was more timely than those in the control group. The timing and number of events reported also improved significantly across all event types when air time was given to the intervention group as shown in Fig. 2, Fig. 3, and Fig. 4. Given the availability of mobile phones in developing countries as a result of easy and low maintenance cost compared to other forms of technology, mobile phones have a huge potential for collecting real-time data. This is because mobile phones could easily be maintained using 'old' parts, and batteries can be charged using car engines, solar panels, or other creative solutions $(22,23)$. Therefore, the HDSS platform could take advantage of the above to improve on the acquisition of data right from the time the event occurred at the community level. This could improve the quality of the data collected and reduce recall bias.

Incorporating the use of a mobile phone in data collection by CKIs on the HDSS platform could be employed to compensate for events that are likely to be missed due to recall bias as a result of the intervals between update rounds. This has become necessary because recall bias can be a threat to both retrospective and prospective research designs hence the need to employ strategies for mitigation (24). There is documented evidence of recall bias associated with surveys characterized by the inability to recall when, and the precise number of times an event took place. $(25,26)$ This may also help to identify and record multiple episodes of events that are likely to occur within the dormant period between update rounds and provide quality which could complement national surveys or censuses which are conducted between long intervals. A challenge identified by this study was the fact that most of the CKIs were above 50 years of age. The majority of the CKIs were aged over 56 years. The energetic youth (26 - 35 years) who could effectively provide voluntary services were about 16 percent. This situation poses a threat to the concept of volunteerism as the youth are not interested in taking up voluntary services. There is, therefore, the need to encourage and provide incentives for the youth to take up voluntary services in their communities to reduce the number of elderly persons providing voluntary services at the community level. Contrary to a study by Wilson (27) where women were seen to be more concerned with community service and would, therefore, be more likely to become volunteers in a study in Zambia, the present study found that 11.7 percent were females. However, findings from a study by Agyemang (3) could explain the low level of female participation in the current study. According to his study, 67 percent of volunteers explained that the work was easier for the male volunteers when they were asked whether their gender made their work easier or difficult for them (3).

Another challenge identified was the number of missed calls. Close to half of the calls were missed, and this may have improved the performance of the intervention. This could be controlled in future scale up by having more than one receiving point. In this study, all calls were received at one receiving point on a particular mobile phone. Providing more receiving points may reduce the number of missed calls as shown in this study. The study did not depend on a particular network provider, CKIs subscribed to their own choice of network. The study had no control on network failure; there may be the need to identify specific geographical locations where certain networks may be assessable considering their coverage. The inability of the study to provide or This study did not examine CKIs' motivation, retention, and incentives. This is because several studies in Ghana and elsewhere sought to investigate what motivates CKIs/CHWs/VHWs/CBSV. Afari-Asiedu et al (28) in their study provided answers to various issues on the concept of volunteerism (28). Agyemang (3) in his study provided evidence on CKI motivation (3). Haberer et al, (4) argued that any monetary incentives would have to be nominal to allow for large-scale implementation, and prior studies have shown that modest monetary compensation can increase study participation rates (4).

Blue Eyes Intelligence Engineering \& Sciences Publication

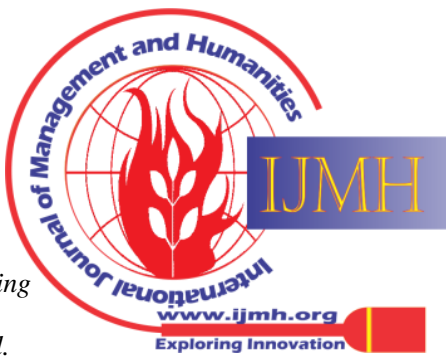


The use of Mobile Phones in Strengthening Health and Demographic Data Collection by Community key Informants: Experiences from the Kintampo Health and Demographic Surveillance System

replace faulty phones may influence the reporting time after event identification. There may be the need to provide or make provision for repairs if this intervention should be scaled up in future studies.

Table- II: Summary statistics of event type reported by CKIs in the intervention and control groups at baseline (in days)

\begin{tabular}{|c|c|c|c|c|c|c|c|}
\hline \multicolumn{2}{|c|}{ Events } & \multicolumn{3}{|c|}{ Intervention } & \multicolumn{3}{|c|}{ Control } \\
\hline \multirow{5}{*}{ Pregnancies } & & $\begin{array}{l}\text { Occur to } \\
\text { identify }\end{array}$ & $\begin{array}{c}\text { Identify to FS } \\
\text { visit }\end{array}$ & Occur to FS visit & $\begin{array}{l}\text { Occur to } \\
\text { identify }\end{array}$ & $\begin{array}{c}\text { Identify to FS } \\
\text { visit }\end{array}$ & $\begin{array}{l}\text { Occur to FS } \\
\text { visit }\end{array}$ \\
\hline & Min & 48 & 0 & 87 & 33 & 1 & 54 \\
\hline & Mean & 65.3 & 129.3 & 92.2 & 56 & 96.0 & 162.6 \\
\hline & Max & 78 & 404 & 134 & 81 & 336 & 254 \\
\hline & $\mathrm{N}$ & 21 & 191 & 21 & 18 & 163 & 18 \\
\hline \multirow{4}{*}{ Births } & Min & 0 & 6 & 7 & 0 & 15 & 15 \\
\hline & Mean & 3.1 & 56.1 & 56.1 & 1.2 & 75.3 & 75.3 \\
\hline & Max & 91 & 430 & 435 & 21 & 158 & 160 \\
\hline & $\mathrm{N}$ & 147 & 165 & 147 & 86 & 88 & 86 \\
\hline \multirow{4}{*}{ Deaths } & Min & 0 & 40 & 41 & 0 & 25 & 25 \\
\hline & Mean & 0.6 & 72.2 & 72.8 & 0.6 & 54 & 54.6 \\
\hline & Max & 1 & 112 & 112 & 3 & 115 & 115 \\
\hline & $\mathrm{N}$ & 5 & 5 & 5 & 10 & 10 & 10 \\
\hline \multirow{4}{*}{ Total } & Min & 0 & 0 & 7 & 0 & 1 & 15 \\
\hline & Mean & 10.6 & 95.1 & 61 & 15.2 & 87.5 & 93.0 \\
\hline & Max & 91 & 430 & 435 & 81 & 336 & 254 \\
\hline & $\mathrm{N}$ & 173 & 361 & 173 & 129 & 265 & 129 \\
\hline
\end{tabular}

Table- III: Summary statistics of event type picked by CKIs in the intervention and control group at end line (in days)

\begin{tabular}{|c|c|c|c|c|c|c|c|}
\hline \multicolumn{2}{|c|}{ Events } & \multicolumn{3}{|c|}{ Intervention } & \multicolumn{3}{|c|}{ Control } \\
\hline \multirow{5}{*}{ Pregnancies } & & $\begin{array}{l}\text { Occur to } \\
\text { identify }\end{array}$ & Identify to call & Occur to call & $\begin{array}{l}\text { Occur to } \\
\text { identify }\end{array}$ & $\begin{array}{l}\text { Identify to FS } \\
\text { visit } \\
\end{array}$ & $\begin{array}{c}\text { Occur to FS } \\
\text { visit } \\
\end{array}$ \\
\hline & Min & 0 & 0 & 27 & 1 & 1 & 54 \\
\hline & Mean & 149.2 & 36.5 & 185.7 & 137.8 & 77.1 & 212.9 \\
\hline & Max & 466 & 186 & 528 & 426 & 247 & 459 \\
\hline & $\mathrm{N}$ & 179 & 179 & 179 & 65 & 68 & 65 \\
\hline \multirow{4}{*}{ Births } & Min & 0 & 0 & 0 & 0 & 0 & 0 \\
\hline & Mean & 25.3 & 28.7 & 54.2 & 4.46 & 75.3 & 79.8 \\
\hline & Max & 403 & 176 & 403 & 60 & 162 & 162 \\
\hline & $\mathrm{N}$ & 188 & 187 & 187 & 80 & 80 & 80 \\
\hline \multirow{4}{*}{ Deaths } & Min & 0 & 0 & 0 & 0 & 0 & 0 \\
\hline & Mean & 5.26 & 22.2 & 25.56 & 1.18 & 110.45 & 111.63 \\
\hline & Max & 59 & 207 & 208 & 6 & 448 & 448 \\
\hline & $\mathrm{N}$ & 46 & 48 & 46 & 22 & 22 & 22 \\
\hline \multirow{4}{*}{ Total } & Min & 0 & 0 & 0 & 0 & 0 & 0 \\
\hline & Mean & 76.8 & 31.4 & 108.1 & 55.9 & 80.6 & 135.8 \\
\hline & Max & 466 & 207 & 528 & 426 & 448 & 459 \\
\hline & $\mathrm{N}$ & 413 & 414 & 412 & 167 & 170 & 167 \\
\hline
\end{tabular}

Published By:

Blue Eyes Intelligence Engineering

\& Sciences Publication

15 (C) Copyright: All rights reserved.

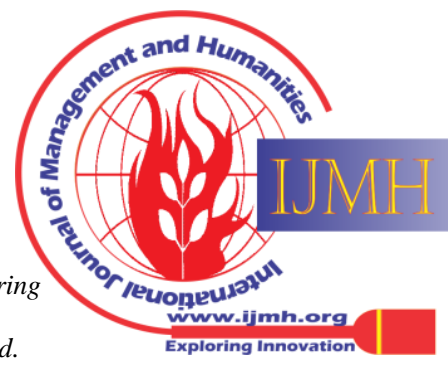




\section{The use of Mobile Phones in Strengthening Health and Demographic Data Collection by Community key Informants: Experiences from the Kintampo Health and Demographic Surveillance System}

\section{CONCLUSION}

The study has demonstrated the feasibility of using a mobile phone in reporting near real-time events which has the potential to improve registration of vital events at the community level within the KHDSS since reporting events using a mobile phone by CKIs in the intervention group was more timely and effective when mobile phone air time was provided. Based on the evidence provided by this study, training and integrating the mobile phone into the CKI system could be scaled with wider targets for intervention in the future. Mobile phone technology could be introduced into the HDSS platform to improved data collection and enhance data quality. The study also recommends further research into how vital events at the community level could be tailored to the District Health Information Management System 2 (DHIMS2). The results from the proposed study will help to include community-level vital events that are usually missed because it does not end in a hospital facility. Additionally, this may help to document if not all data on vital events that happen in the community to be accounted for decision making by stakeholders.

\section{ACKNOWLEDGMENT}

The authors wish to thank the Management and staff of KHRC for introducing and funding young researchers as part of the Director's Small Grant initiative. The team is also grateful to the CKIs for their time and participation in this study. The next appreciation goes to the entire KHDSS team and FS for their enormous contribution to this study. Lastly, we would like to thank the community members of the Kintampo North Municipality and Kintampo South District for making this study a success.

\section{REFERENCES}

1. WHO. Strengthening civil registration and vital statistics for births, deaths and causes of death Resource Kit. 2012; Available from: www.who.int/healthinfo/CRVS_ResourceKit 2012.pdf

2. United Nations Development Programme. UNDP suport to the Implementation of Sustainable Development Goal 3: Ensure healthy lives and Promote well-being for all at all ages. Sustain Dev Goals [Internet]. 2017;20. Available from: http://www.undp.org/content/undp/en/home/sustainable-development-g oals/goal-3-good-health-and-well-being.html

3. Agyemang D. INCENTIVES AND DISINCENTIVES OF COMMUNITY HEALTH WORKERS IN GHANA [Internet]. 2014. Available

from: www.linkedin.com/pulse/incentives-disincentives-community-health-w orkers-ghana-agyemang/?trk=pulse-det-nav art \%0A

4. Haberer JE, Kiwanuka J, Nansera D, Wilson IB, Bangsberg DR Challenges in using mobile phones for collection of antiretroviral therapy adherence data in a resource-limited setting. AIDS Behav. 2010;14(6):1294-301.

5. Beguy D, Elung'ata P, Mberu B, Oduor C, Wamukoya M, Nganyi B, et al. Health \& Demographic Surveillance System Profile: The Nairobi Urban Health and Demographic Surveillance System (NUHDSS). Int J Epidemiol. 2015;44(2):462-71.

6. Owusu-Agyei S, Nettey OEA, Zandoh C, Sulemana A, Adda R, Ghana: baseline indicators from the Kintampo Health and Demographic Surveillance System. Glob Health Action. 2012;5(June 2014):1-11.

7. Kim Streatfield P, Khan WA, Bhuiya A, Hanifi SMA, Alam N, Millogo O, et al. HIV/AIDS-related mortality in Africa and Asia: Evidence from Health Action. 2014;7(1).

8. Kaneko S, K'opiyo J, Kiche I, Wanyua S, Goto K, Tanaka J, et al. Health and demographic surveillance system in the western and coastal Amenga-Etego S, et al. Demographic patterns and trends in Central INDEPTH health and demographic surveillance system sites. Glob

areas of kenya: An infrastructure for epidemiologic studies in Africa. J Epidemiol. 2012;22(3):276-85.

9. Boulos MNK, Wheeler S, Tavares C, Jones R. How smartphones are changing the face of mobile and participatory healthcare : an overview, with example from eCAALYX. Biomed Eng Online [Internet] 2011;10(1):24. Available from: http://www.biomedical-engineering-online.com/content/10/1/24

10. Bank WG. Digital DiviDenDs world development report OveRvieW A World Bank Group Flagship Report [Internet]. 2016. Available from: www.reboot.org

11. Burns C. WHO International Standards/Reference Reagents. Glob Obs eHealth Ser [Internet]. 2011;3:99. Available from: http://www.who.int/about/\%0Ahttp://www.who.int/goe/publications/go e_mhealth_web.pdf

12. Kintampo Health Research Centre. ANNUAL REPORT 2017 [Internet]. 2017. Available from: www.kintampo-hrc.org

13. Kintampo Health Research Centre. Annual Report 2011 [Internet]. 2011. Available from: www.kintampo-hrc.org.

14. 14. Tomlinson M, Solomon W, Singh Y, Doherty T, Chopra M, Ijumba $\mathrm{P}$, et al. The use of mobile phones as a data collection tool: A report from a household survey in South Africa. BMC Med Inform Decis Mak. 2009;9(1):1-8.

15. Braun R, Catalani C, Wimbush J, Israelski D. Community Health Workers and Mobile Technology: A Systematic Review of the Literature. 2013;8(6):4-9.

16. Dil Y, Strachan D, Cairncross S, Seidu A, Zelee K. Motivations and Challenges of Community-Based Surveillance Volunteers in the Northern Region of Ghana. 2012;

17. Afele M. Volunteers vital for counting births and deaths in Ghana. Bull World Health Organ. 2011;89(5):322-3.

18. Koku Awoonor, Niagia Santuah, Amerley Ollenu, Joan Awunyo-Akaba, Bibiana Bangpouri, Caroline Tetteh KAB COMMUNITY HEALTH VOLUNTEER'STraining Manual [Internet] 2009. 18-20 p. Available from: www.popcouncil.org/uploads/pdfs/2009CHPS TrainingManualCHVol unteers.pdf

19. Ihatpsm. Registration of Vital Events:www.ihatepsm.com/blog/1-registration-vital-events-civil-regist ration-system.

20. Microsoft. Visual FoxPro 9.0, Visual FoxPro Developer Centre Microsoft. 2007; Available from: www.microsoft.com

21. STATA. StataCorp. 2011. Stata: Release 12. Statistical Software. College Station, TX: StataCorp LP.

22. Leach-Lemens C. Using mobile phones in HIV care and prevention [Internet]. HATiP - HIV \& AIDS Treatment in Prectice. 2009. p. 2-8. Available

from: https://www.aidsmap.com/news/may-2009/using-mobile-phones-hiv-c are-and-prevention

23. The Vodafone Policy Paper Series. The role of mobile phones in increasing accessibility and efficiency in healthcare [Internet]. 2006 Available from:

https://manualzz.com/doc/13382713/the-role-of-mobile-phones-in-incr easing-accessibility-and..

24. Hassan E. Recall Bias can be a Threat to Retrospective and. Internet Epidemiol. 2005;3(2):1-7.

25. Kjellsson G, Gerdtham U. Forgetting to Remember or Remembering to Forget - A Study of the Recall Period Length in Health Care Survey Questions. 2013;(January).

26. Brusco NK, Watts JJ. Empirical evidence of recall bias for primary health care visits. BMC Health Serv Res [Internet]. 2015;1-8. Available from: http://dx.doi.org/10.1186/s12913-015-1039-1

27. Wilson T. Incentives and volunteerism in Zambia: A review. Research Partnerships Build the Service Field in Africa,Special Issue on Civic Service in the Southern African Development Community. 2007. p. 68-84.

28. Afari-Asiedu S, Asante KP, Senah K, Abdulai MA, Afranie S, Mahama E, et al. Volunteering for Health Services in the Middle Part of Ghana: In Whose Interest? Int J Heal Policy Manag [Internet]. 2018 May 5 [cited 2019 Jan 15];7(9):836-46. Available from: http://ijhpm.com/article_3494.html

29. B. Smith, "An approach to graphs of linear forms (Unpublished work style)," unpublished.

30. E. H. Miller, "A note on reflector arrays (Periodical style-Accepted for publication)," IEEE Trans. Antennas Propagat., to be published. 
31. J. Wang, "Fundamentals of erbium-doped fiber amplifiers arrays (Periodical style-Submitted for publication)," IEEE J. Quantum Electron., submitted for publication.

32. C. J. Kaufman, Rocky Mountain Research Lab., Boulder, CO, private communication, May 1995.

33. Y. Yorozu, M. Hirano, K. Oka, and Y. Tagawa, "Electron spectroscopy studies on magneto-optical media and plastic substrate interfaces(Translation Journals style)," IEEE Transl. J. Magn.Jpn., vol 2, Aug. 1987, pp. 740-741 [Dig. $9^{\text {th }}$ Annu. Conf. Magnetics Japan, 1982 , p. 301].

34. M. Young, The Techincal Writers Handbook. Mill Valley, CA: University Science, 1989.

35. (Basic Book/Monograph Online Sources) J. K. Author. (year, month, day). Title (edition) [Type of medium]. Volume(issue). Available: http://www.(URL)

36. J. Jones. (1991, May 10). Networks (2nd ed.) [Online]. Available: http://www.atm.com

37. (Journal Online Sources style) K. Author. (year, month). Title. Journal [Type of medium]. Volume(issue), paging if given. Available: http://www.(URL)

\section{AUTHORS PROFILE}

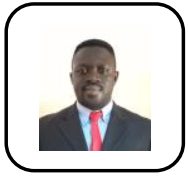

Edward Anane Apraku, holds BA IDS (Social and Development Administration) from the University for Development Studies, Tamale Ghana, and MSC in Public Health Monitoring and Evaluation from the University of Ghana. He has other trainings in Monitoring and Evaluation in Global Health, and Project Management in Global Health from the University of Washington, United States of America.

Edward is a Research Fellow at the Kintampo Health Research Centre. He worked as a Research Officer with the Kintampo Health and Demographic Surveillance System (KHDSS) from 2012 to 2018 and coordinated the day to day activities of the system. His activities included monitoring the fertility, mortality and migration patterns of the population covered by the HDSS. He also Coordinated the conduct and clinical coding of Verbal Autopsy which sought to ascertain the causes of death within the population. He happened to be part of the field workers who demarcated and enumerated the initial census of the KHDSS when it was finally extended to cover every community in the catchment area in 2003. Edward has in-depth research experience in field data collection, training, questionnaire design, survey design, and the application of quantitative and qualitative method. He has vast experience in project management, monitoring and evaluation with a key interest in impact evaluation. He was a co-investigator of a Small grant award from USAID/Ghana Evaluate for Health to conduct a research on the Utilization of the DHIMS 2 data for health service Decision making at the District, Sub-District, and the Community Levels in the Bono Ahafo Region of Ghana. 2017. He has a number of publication to himself https://www.semanticscholar.org/author/Edward-Anane-Apraku/20061966 $\underline{45}$

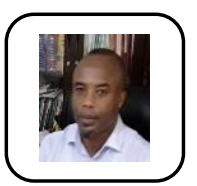

Abubakari Sulemana, holds Bachelor of Arts degree (Geography and Economics), MPhil degree (Geography \& Resource Development), PhD degree in Population Studies. Sulemana has about a decade and a half experience in population/community based health research. He was the head of the Kintampo Health and Demographic Surveillance System (Kintampo HDSS), a department of KHRC between 2005 and 2013. As the head of the Kintampo HDSS, he coordinated the implementation of a number of health research activities. These included the household biomass fuel use, adolescent sexual and reproductive health, fertility, tuberculosis, HIV/AIDS, female genital mutilation/cutting, malaria, household bed-net use, Intermittent preventive treatment in pregnancy, Mental Health and Poverty Project (HDSS Module of the MHAPP), Access module of the INDEPTH phase IV Effectiveness and Safety Studies (INESS) of antimalarials in Africa. In addition, he coordinated all Kintampo HDSS activities such as routine updates on pregnancies, births, deaths, migration-in, migration-out, household socio-economic status, immunization as well as the conduct of verbal autopsy and the coding of causes of death by physicians. Furthermore, he played key role in other KHRC health research activities. Notable among them were health surveys in Asutifi, Tano North and South districts, Birim North and South districts, the Ahafo Mining Area Health and Demographic Surveillance System, Health and Demographic Surveillance activities in Nkoranza North District, Nkoranza South Municipality, Techiman North District and Techiman South Municipality as well as CHPS Verification survey across all regions of Ghana.

Sulemana was awarded certificate of excellence in reviewing by the Journal of Advances in Medicine and Medical Research in 2019. He served as a reviewer for submissions to the JBI Database of Systematic Reviews and Implementation Reports as well as the 2019 National Health Research Dissemination Symposium. He also leads and contributed to the preparation of several successful grant applications at the Kintampo Health Research Centre. He is currently part of a team of researchers working on Household air pollution in Ghana through community-level transitions to clean cook stoves and fuels.

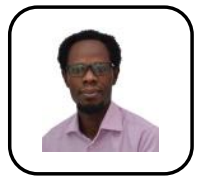

Francis Dzabeng is a young research scientist with keen interest in Evidence-based Healthcare \& Practice and genomic data science. He graduated with a BSc (Hons). in Applied Chemistry from University for Development Studies, MSc degree in Health Informatics from University of Ghana and a Post-graduate diploma in Advanced Computing (Wireless Mobile Computing) from the Centre for Development of Advanced Computing, Pune, India. Francis has more than 10 years of practical experience in public health research, data science and technical computing. He was a Research Fellow/Snr. Data Manager working with Kintampo Health and Demographic Surveillance System and INDEPTH - Every Newborn Action Plan Metrics - A multi-center project involving five (5) INDEPTH Network Health Demographic Surveillance (HDSS) sites. He is currently working at West African Centre for Cell Biology of Infectious Pathogens, University of Ghana as a Data Manager \& Statistician.

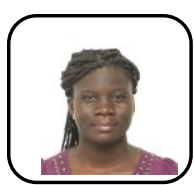

Awurabena Quayeba Dadzie, is currently the Health Technical Project Manager of World Vision Ghana and a Public Health Specialist with more than 7 years' experience in Community-Based Health Interventions, Social Behavioural Change Communications, Public Health Research Interventions to inform policy, public health advocacy and interventions in communicable and non-communicable diseases. Over the years she worked with the Kintampo Health Research Center, University of Ghana (School of Public Health and Department of Psychology), Ministry of Health, Ghana Health Service, Ghana AIDS Commission and other Community Based Organizations in implementing Public Health Interventions. She has a Master's in Public Health with specialization in Health Systems Policy and Management and International Course in Health and development at the Royal Tropical Institute, Amsterdam Netherlands. She has worked on several international and local health projects in communicable and non-communicable diseases comprising of Malaria, HIV/AIDS, Maternal and Neonatal Child Health, TB and Nutrition, Family Planning, Sexual and Reproductive Health \& Rights and NTDs. She has strong Qualitative and Quantitative Research Skills for data collection and good Monitoring and evaluation skills in public health interventions and building community systems. Throughout her work she has both published and unpublished research papers to her credit.

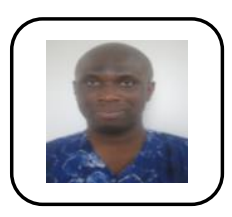

Ernest O. Nettey holds BA Psychology and Philosophy, University of Ghana, MPhil Population Studies, Regional Institute for Population Studies, University of Ghana, PhD Population Studies, Regional Institute for Population Studies, University of Ghana. Research Fellow and Demographer, Kintampo Health Research Centre (KHRC), Ghana and worked directly under the Kintampo Health and Demograohic Surveillance System. Ernest is a member of the Population Association of America (PAA), and the International Union for the Scientific Study of Population (IUSSP). He has ind-depth knowledge in health research and served as a co-investigator on Every Newborn Action Plan Project -A randomized comparison of household survey modules for measuring pregnancy outcomes in five INDEPTH HDSS sites, Ghana Adolescent Reproductive Health Programme- Enhancing sexual and reproductive health service delivery to adolescents in Ghana: perspectives from adolescents and other stakeholders in the BrongAhafo Region, and the Measure Evaluation Small Grants Programme on Improving Family Planning (FP) Service Delivery to Adolescents in Ghana. He has a number of publication https://www.semanticscholar.org/author/O.-E.-Nettey/84364039 $\quad$ His research interest includes Demographic, Epidemiological Trends and Transitions; Health and Mortality in Lower Middle-Income Countries (LMICs), Fertility and Reproductive Health; Population, Socio-economic Development Interrelationships and Inequalities in LMICs;

Blue Eyes Intelligence Engineering $\&$ Sciences Publication

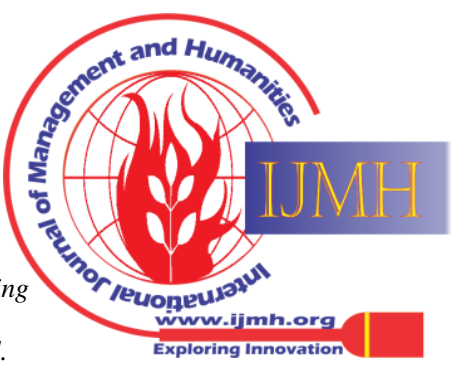




\section{The use of Mobile Phones in Strengthening Health and Demographic Data Collection by Community key Informants: Experiences from the Kintampo Health and Demographic Surveillance System}

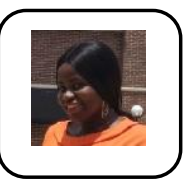

Gifty Fosuah Nuamah holds a BSc Geography and Rural Development from the Kwame Nkruamah Univerity of Science and Technology, Kumasi Ghana, and MA in Development Studies, Social Policy for Development from Erasmus University Rotterdam. She has key interest in Child and Youth Policy Analysis and Development Gifty worked as a research officer at the Kintampo Health Research Centre under the Kintampo Health and Demographic Surveillance System. She managed and coordinated the activities of field workers and field supervisors. She has experience in field data collection, training, monitoring and survey designs. She has experience in project management and coordinated projects such as the Neonatal Quality Improvement Programme (NQIP) between 2011 and 2012 as a site coordinator. She also coordinated the activities of Community key informants who provided information on vital events in their respective communities. Her research interest includes maternal health, adolescent and reproductive health research.

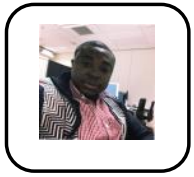

Samuel Afari-Asiedu is a Research Fellow and a Medical Sociologist with over 10 years' experience in public health research at the Kintampo Health Research Center, Research and Development Division of the Ghana Health Service. He hold a BA and MPhil in Sociology. Samuel is also a final year PhD student at the Radboud University Medical Center in the Netherlands. His research interest is in exploring the nexus between society and health within a broader context of social determinants of health and the use of medicine. His research is therefore focused on access and use of medicines and health seeking behaviours at the community level in low and middle income countries. Over the years, he has conducted studies in the areas of sexual and reproductive health, maternal health, malaria and implementation research, health systems research, adoption of clean cooking fuels etc. He has in-depth knowledge and skills in quantitative and qualitative research methods. In the recent 5 years, his research interest and activities have mainly revolved around antibiotic stewardship at the community level i.e community antibiotic access and use. Through an international collaborative study funded by Wellcome trust and his $\mathrm{PhD}$, he has been exploring the contextual determinants of antibiotic access and use (ABACUS I) in LMIC (Africa and Asia) to identify targets to improve on access and use at the community level. Building on the findings from ABACUS I (Scientific Publications ABACUS project (abacus-project.org), his team through another Wellcome Trust initiative is currently exploring the case for a standardized appearance of oral antibiotics ABACUS II project in Europe, Africa and Asia.

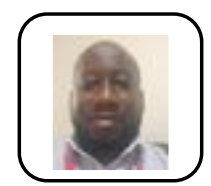

Emmanuel Mahama, Bsc. Mathematic and Statistics, Msc Medical Statistics, and a Post Graduate Diploma in Medical Statistics. Emmanuel is a monitoring and evaluation (M\&E) specialist and a Medical Statistician by profession, public health epidemiologist and researcher. Mr. Mahama has 16 years of experience in researching monitoring, managing, and building capacity for community-based and institution-based interventions across a wide range of health sector, including newborn, maternal and child survival, health systems strengthening, malaria epidemiology, health information management systems, sexual and reproductive health, family planning, infection control, nutrition and HIV/AIDS. Mr. Mahama has extensive experience working with health project staff to develop results frameworks, indicators, PMPs and data collection instruments, and to carry out Data Quality Assessments (DQAs) and develop data quality strategies. He also has in-depth research skills, including application of quantitative and qualitative methodologies. He also served as Medical Statistician Specialist for the Kintampo Health Research Center on studies related to malaria and maternal and child mortality including large scale clinical trials.

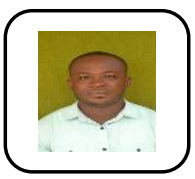

Mahama Abukari is a young Researcher with a demonstrated history of working in the health sector in Ghana. Skilled in Analysis, Coordination, Supervision and management of fieldwork and Data Collection teams. A strong research professional with a Master of Philosophy - MPhil focused in Health Systems Research and Management from Kwame Nkrumah University of Science and Technology, Kumasi-Ghana. Strongly interested in research into strengthening and improving health systems and how research output is utilized to improve health systems.

In 2008 he begun research work as Mapping Assistant and later a Field Supervisor at the GSS (FOGIS) to work on the Ghana National Population and Housing Census 2010 Field Demarcation Programme. This was a cartographic fieldwork aimed at dividing the country into smaller units of Enumeration. In 2011, he joined KHRC as a research officer assigned to the
Ahafo Mining Area Health and Demographic Surveillance System (AMAHDSS). The AMAHDSS was a platform for gathering demographic and health data to monitor and assess the impact of mining in the Asutifi and Tano Districts of Ghana. He coordinated and supervised fieldwork on the Ahafo Health Impact Assessment Survey. Currently he is assigned to the Kintampo Health and Demographic Surveillance System as a research officer.

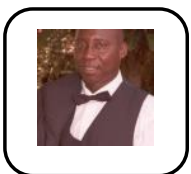

Charles Zandoh holds BA, MSc Medica demograph, he has been involved in epidemiological and Demographic health research since 1995 . He has conducted several health survey and also established demographic surveillance in the research areas of Kintampo Health Research Centre. (Ahafo Mining Area Health and Demographic Surveillance, Nkoranza North Health and Demographic Surveillance System, Techiman North Health and Demographic Surveillance System all under the Kintampo Health Research Centre. He has been part of several teams conducting various demographic and epidemiological research at the centre. Charles has a lot of health research experience having worked as the head of fieldwork for the following projects: EPI++ project from 1995 to 1998, which looked at administering vitamin A supplement at the time children receive their routine EPI vaccines ObaapavitA 2000 to 2008, looking at the effect of Vitamin A supplementation among women of reproductive health on materna mortality. He was also involved in the setting up of the various Health and Demographic Surveillance System (HDSS) of the Kintampo Health Research Centre and currently the head of the HDSS. Charles research interest include maternal and child health research, sexual and reproductive health, and non-communicable disease research.

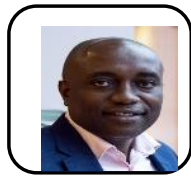

Dr. Kwaku Poku Asante holds a BSc. in Medica Sciences, MD degree, Masters in Public Health from the premier University of Ghana and a PhD from the London School of Hygiene and Tropical Medicine, UK Dr. Asante is currently the Director at Kintampo Health Research Centre in Ghana and the Trial Director for the Ghana Randomized Air Pollution and Health Study (GRAPHS). Until his appointment, he was the Head of Research at KHRC. Between 2006 and 2013, Dr. Asante was the Head of Malaria Research and led research teams to implement Phase II and III malaria vaccine and drug trials. He has led research projects as a principal investigator in several African Countries including Ghana, Burkina Faso, Kenya, Guinea, and Uganda. He has received research grants from the Government of Ghana, Wellcome Trust, USAID, USA National Institute of Health, Global Alliance for Clean Cookstoves, Thrasher Research Fund, Anglogold Ashanti Malaria Control Program/ Global Fund among others. Dr. Asante is currently the Chairman of the African Clinical Trials Partnership Committee of investigators; committee of African and other international experts with the aim of conducting clinical research in Africa.Dr. Asante is an Adjunct Lecturer at University of Ghana School of Public Health. He has communicated his research findings in over 60 peer reviewed publications and on local and international media platforms such as BBC Focus on Africa, Aljazeera Doha Report, Ghana Broadcasting Cooperation, and several radio stations. Dr. Asante is a co-recipient of the 2008 Prince of Asturias Foundation Award; an institutional award of the Prince of Asturias Prize for International Cooperation to Kintampo Health Research Centre under his tenure of Head of Malaria Research; a recipient of The United States of America Centre for Disease Control's 2015 Charles C. Shepard Science Award in the category of Prevention and Control; and a recipient of the 2016 Professional Excellence Award.

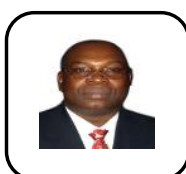

Professor Seth Owusu-Agyei is the Pro-Vice Chancellor of the University of Health and Allied Science in Ho, Ghana. Prior to this, he was the Director of Kintampo Health Research Centre, Ghana Health Service/Ministry of Health and a Senior Lecturer in the Faculty of Infectious Tropical Diseases in the London School of Hygiene and Tropical Medicine. He is an epidemiologist. Education: He had his basic degree education at the University of Ghana, Legon, a Master of Science degree in Applied Medical Parasitology at the Liverpool School of Tropical Medicine and a PhD in Epidemiology at the Swiss Tropical Public Health Institute, Basel, Switzerland.

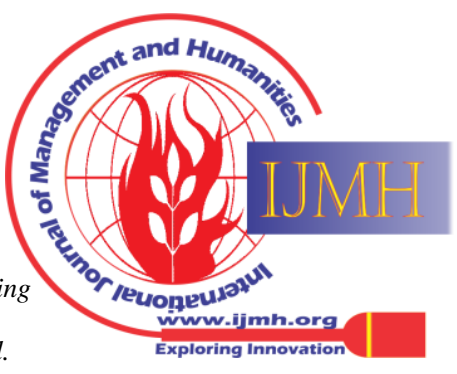


He started his research career at Noguchi Memorial Institute for Medical Research, University of Ghana some 30 years ago; he later moved to Navrongo to work as a pioneer staff on the Ghana Vitamin A Supplementation Trials which later became the Navrongo Health Research Centre (NHRC). He undertook several research studies in field/clinical epidemiology in Navrongo and served several years as a management member. He was later appointed as the Director of Kintampo Health Research Centre (KHRC) under the Research and Development Division of the Ghana Health Services where he served in this capacity for 14 years. He spearheaded research, diversifying the scope, expanding on research collaborations with various research institutions, attracting funders to KHRC and building both human and infrastructural capacity required for excellent research. He has been Principal Investigator for several large-scale field/clinical intervention studies/trials in Ghana. Of special mention is

studies carried out on the most advanced malaria vaccine that is very close to licensure as the first ever malaria vaccine to be deployed. Science /Research output: Professor Owusu-Agyei's main area of research is infectious disease epidemiology, especially malaria. He has extensive experience in the design and implementation of large and longitudinal studies and is well known in maternal, neonatal and child health intervention studies as well as in non-communicable diseases research. He has served as member of several WHO Committees as temporary advisor. He was a board chair of the INDEPTH network for 4 years. He has served on several local and international committees and boards. He has over 200 publications in peer-reviewed journals, several Technical reports conference presentations, and has co-authored 4 books.

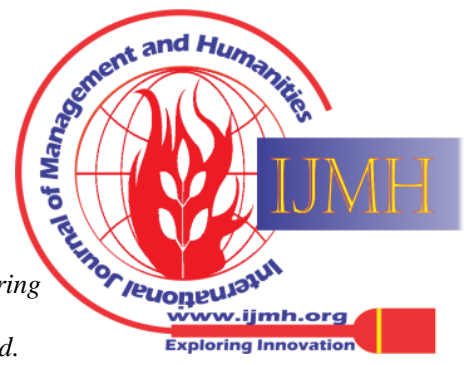

